\title{
EXPERIMENTAL AND NUMERICAL INVESTIGATIONS ON HISTORICAL MASONRY WALL SPECIMENS TESTED IN SHEAR-COMPRESSION CONFIGURATION
}

\author{
Franco DI FABIO, Amedeo GREGORI, Matteo TOTANI \\ Department of Civil, Building and Environmental Engineering, University of L'Aquila, \\ Via G. Gronchi 18, 67100, L'Aquila, Italy
}

Received 13 November 2015; accepted 19 January 2016

\begin{abstract}
The paper presents the experimental investigation carried out on wall specimens reproducing the ancient masonry of several monumental building located in the old city centre of L'Aquila (Italy) and damaged by the April 2009 earthquake. The wall specimens were prepared in accordance with the traditional technique, using original stone elements and typical poor mortar. Subsequently, the specimens were consolidated with mortar injections. Other specimens were also reinforced with Ultra High Tensile Strength Steel wires applied as coating technique (not wrapped). Shear-compression tests were carried out on the wall specimens to evaluate the effects of the reinforcements both in terms of final stiffness and strength of the specimens. A non-linear Finite Element Model (FEM) was developed to reproduce the experimental tests and to better understand the damage phenomena. The load-displacement curves predicted by the FEM compared quite well with the experimental ones. The failure mode of the specimens was properly captured by the FEM. The effectiveness of the external reinforcement was proved to strictly depend on the coating adhesiveness to the walls surface. The premature debonding of the external reinforcement was demonstrated to cause the fragile post-peak behaviour during both the actual experimental test and the numerical simulations.

Keywords: historical masonry, retrofitting, UHTSS wire, debonding failure mode, experimental tests, FEM analysis.
\end{abstract}

\section{Introduction}

LAquila is a medieval walled city (13th century) located in the Abruzzo Region (central Italy) and rich in historical buildings of considerable merit. In April 6, 2009 a devastating earthquake (Richter magnitude $\mathrm{M}_{\mathrm{L}}=5.8$; Moment magnitude $M_{W}=6.2$ ) hit the town and many surrounding villages, causing hundreds of fatalities, thousands of injuries, extensive and severe damages to buildings and infrastructures (Chiaraluce et al. 2009; Ameri et al. 2009; Chioccarelli et al. 2009). Historical masonry buildings suffered from very heavy damages, their global collapse being in most cases avoided by tie and rods, anchor plates and other simple but effective earthquake-resistant presidium present due to the historical seismic nature of the land (Ceci et al. 2010). However, poor connections among orthogonal masonry walls, reduced floors stiffness, wrong mass distribution and absence of restraints to out-of-plane wall mechanisms were recognized as the causes for collapse of most masonry buildings (Dominici et al. 2011, 2012, 2014). Most of these buildings are characterized from a similar masonry typology, the physical and mechanical properties of which start now to be properly investigated. The present research deals with the experiments curried out on wall specimens reproducing the original wall texture recognized in Palazzo Camponeschi (XVI century). The original materials and constructive techniques adopted in this research 
are representative of a large number of ancient construction types spreading in the old city centre and in the whole surrounding territory.

\section{Palazzo Camponeschi features}

Palazzo Camponeschi is a monumental masonry building standing in the old city centre of L'Aquila. The original building plan probably dates before the 16th century, but several modifications to the original building structure were introduced in the following centuries (Fig. 1).

From an architectural point of view, a general description of the building is provided in Ceci et al. (2010) and in Dominici et al. (2014). From a structural viewpoint, Palazzo Camponeschi's original resistant system consists of vertical masonry walls composed of irregular stone units and poor lime-clay mortar joints. Large inclusions of bricks or other low-quality materials are found in the masonry volume, so that a chaotic masonry texture is generally recognized in the building (Fig. 2).

Moreover, massive walls of the ancient masonry buildings often consist of two external layers (made of poor quality stone masonry) and a weak internal core (of various thickness) made of debris, rubble and soil introduced as filling material. The resisting part of this multilayer system is represented by the two outside layers; these two external panels often work independently of each other due to the lack of interconnection through the wall thickness. Because of this, in situ mechanical tests performed on multilayer masonry walls often provide the properties of the external layers only.

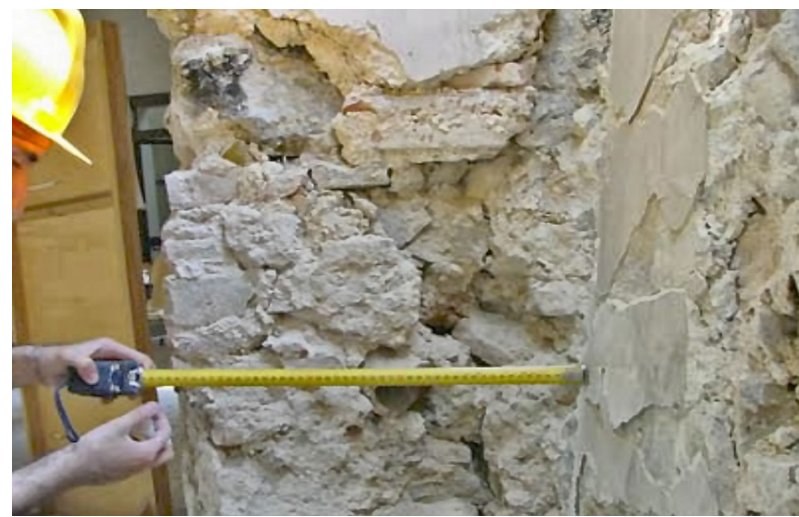

Fig. 2. Chaotic masonry texture made of irregular stone units, poor lime-clay mortar and large inclusions of bricks

For instance, the effective wall thickness investigated with a flat jack apparatus is usually limited in the range of few hundred millimetres. Performing an in situ diagonal test represents the only option to investigate the mechanical performance of a masonry wall referring to its global thickness. Although this technique provides highly reliable results, it is not frequently used in situ. This is due to the high cost, the practical difficulties involved, and the extensive damage caused to the original wall. On the other hand, diagonal tests are often preferred for laboratory investigations, most of the time on wall panels made of bricks and regular mortar layers for which standards already exist about the specimen preparation and the test execution (EN 1052-3:2007). Unfortunately, no standards exist about mechanical tests on laboratory masonry wall samples made of irregular stone elements distributed in a chaotic texture.
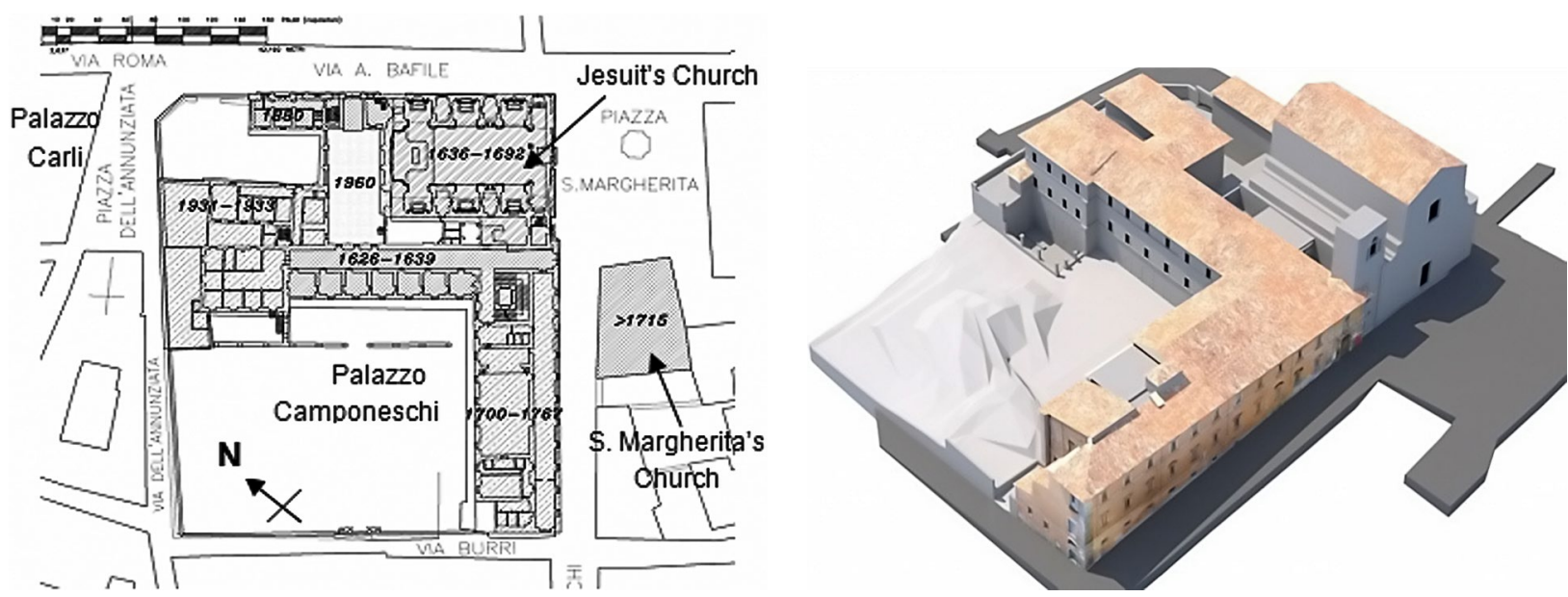

Fig. 1. Building date of constituent parts of Palazzo Camponeschi's aggregate, also including the old Jesuit's Church (on the left); rendering of Palazzo Camponeschi (on the right) 
In this paper, the laboratory tests carried out on wall specimens reproducing the historical masonry texture of Palazzo Camponeschi are presented. The experimental set-up, the specimens preparation, the test execution and the preliminary results obtained are critically discussed in the following paragraphs.

\section{Materials and settings}

Several wall specimens about $500 \mathrm{~mm}$ long, $500 \mathrm{~mm}$ high and $300 \mathrm{~mm}$ thick were prepared with the original limestone elements and the constructive techniques recognized in Palazzo Camponeschi. The average diameter of the stone elements was in the $120-150 \mathrm{~mm}$ range. The original mortar features (characterized by being very friable with a compressive strength lower than $2 \mathrm{MPa}$ ) were reproduced according to the 1:2.5 ratio between commercial calcium hydroxide (in powder) and local, crashed limestone sand including large clay percentage. Water was added to the mortar mixture till a plastic consistency was reached. The original wall texture in Palazzo Camponeschi and that reproduced with the laboratory wall specimens are compared in Figure 3.

A first wall specimen (referred to as the prototype) was prepared and kept undisturbed for a curing period of about 30 days, so allowing the mortar to hard in the air (at room conditions). Subsequently, the prototype specimen was tested in compression and a compressive strength value of about $0.6 \mathrm{MPa}$ was recorded. This performance was considered in good agreement with data provided by D.M. 14/1/2008 and by Circolare 614/2009 for a similar masonry typology (irregular stone elements and mortar layers in a chaotic texture).

Additional four wall specimens were then prepared and cured in accordance with the aforementioned procedure. Due to the very low mechanical performance of the basic masonry, any sort of activity like transportation and storage on the wall specimens was considered dangerous for the specimens integrity. Bare masonry specimens were thus considered unsuitable for the test and it was assumed that all the specimens had to be, at least, consolidated with mortar injection. For this reason, the original mortar joints were previously brushed, deeply cleaned and closed up with new mortar. Subsequently, the wall specimens were consolidated with injections of a liquid mixture made of cementitious materials and other fillers. The mortar recipe remained secret for commercial reasons. Two of the four already injected wall specimens were reinforced later on with a fabric made of Ultra High Tensile Strength Steel wires (UHTSS) applied, as coating technique, on the $500 \times 500 \mathrm{~mm}$ external surfaces of the specimens (Fig. $4 \mathrm{~b}$ ). On each side of the wall specimens, the outer reinforcement resulted in a single sheet of UHTSS fabric embedded in a mortar layer 15 $\mathrm{mm}$ thick. The mechanical behaviour of wall specimens consolidated with mortar injections and also reinforced with UHTSS fabric was compared to that of the masonry wall specimens consolidated with mortar injections only. Both types of retrofitting techniques (mortar injection only or in combination with external reinforcement) are extensively used in current practice.
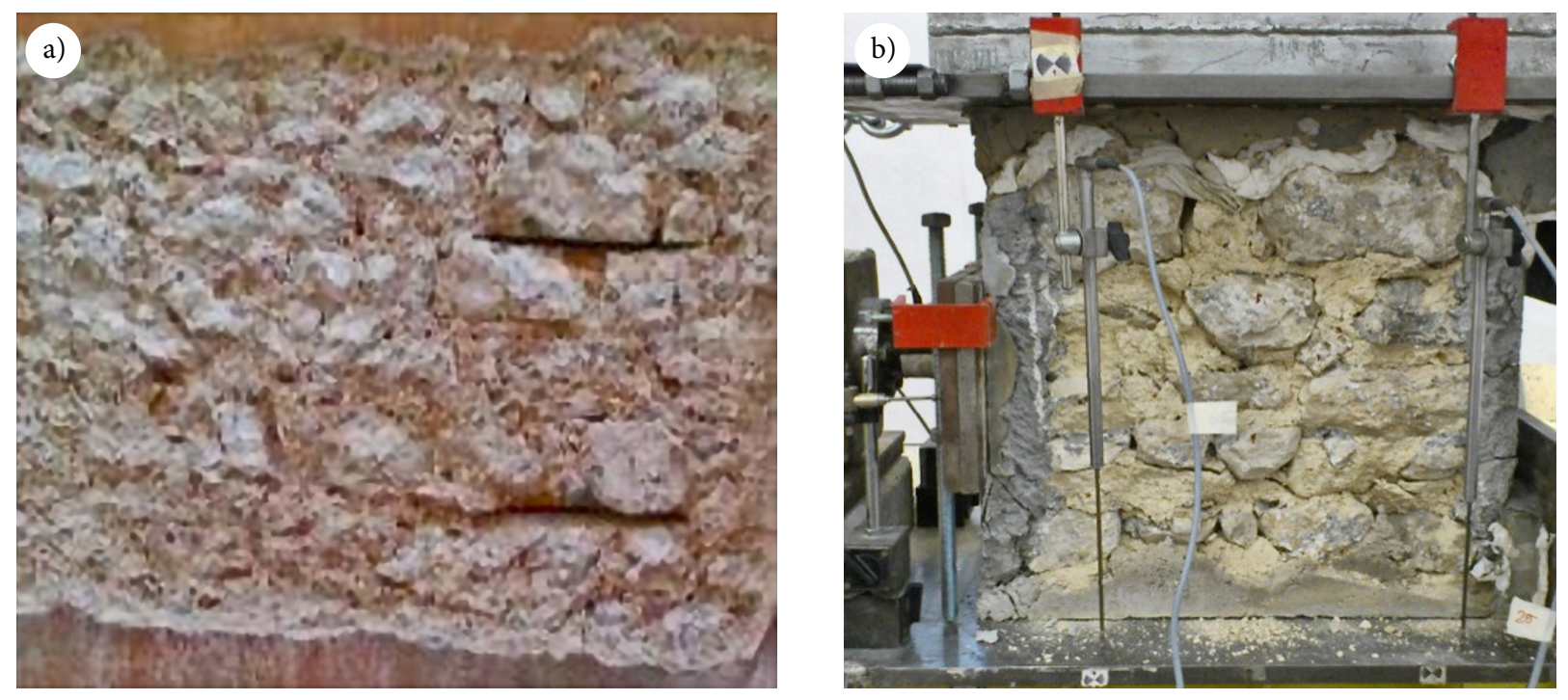

Fig. 3. The original texture of the masonry wall in Palazzo Camponeschi (a) and laboratory wall specimens reproducing it (b) 
Table 1. List of wall specimens tested

\begin{tabular}{|c|c|c|c|c|c|c|c|c|}
\hline \multirow{2}{*}{ Specimens \# } & \multicolumn{4}{|c|}{$\begin{array}{c}\text { Nominal dimensions (mm) } \\
\text { (before the application of the } \\
\text { reinforcement) }\end{array}$} & \multicolumn{2}{|c|}{ Reinforcement type } & \multicolumn{4}{|c|}{$\begin{array}{c}\text { Final dimensions after the } \\
\text { reinforcement application } \\
\text { (mm) }\end{array}$} \\
\cline { 2 - 10 } & Thickness & Length & Height & Internal & External & Thickness & Length & Height \\
\hline 1 & 300 & 500 & 500 & Mortar injection & - & 300 & 500 & 500 \\
\hline 2 & 300 & 500 & 500 & Mortar injection & - & 310 & 550 & 560 \\
\hline 3 & 300 & 500 & 500 & Mortar injection & UHTSS & 330 & 540 & 545 \\
\hline 4 & 300 & 500 & 500 & Mortar injection & UHTSS & 335 & 535 & 505 \\
\hline
\end{tabular}

Nominal and final dimensions of the wall specimens (before and after the application of the external reinforcement) are displayed in Table 1. Compared to nominal dimensions, a slight increase in thickness resulted from the application of the external reinforcements. Due to the irregularity of the original stone elements, additional operations were needed to make the sides of the specimens perfectly regular and plane before performing the mechanical tests. This determined small differences between nominal and final dimensions of the specimen length and height.

\subsection{Wall specimens reinforced with UHTSS}

The UHTSS consists of a unidirectional ultra-high tensile strength steel sheet made of high carbon steel cords with a micro-fine zinc galvanized coating. The cords are made by five individual wire filaments twisted together and fixed on a thermosetting grid. A photo of the UHTSS is given in Figure 4a. Geometrical and mechanical properties of the UHTSS have been determined according to the UNI and ASTM standards as indicated in CNR DT 200/204: 2004 and are provided in Table 2.

In this study, a premixed lime-based mortar was used to encase the UHTSS on both sides of the specimens. A single sheet was arranged with cords oriented in the vertical direction. The reinforcing sheet was not wrapped around the specimens but just interrupted at
Table 2. Geometrical and mechanical properties of the UHTSS

\begin{tabular}{|l|c|}
\hline Filament area & $0.1076 \mathrm{~mm}^{2}$ \\
\hline Effective area of one cord (5 filaments) & $0.538 \mathrm{~mm}^{2}$ \\
\hline $\begin{array}{l}\text { Average number of cord found in a cm } \\
\text { of sheet }\end{array}$ & 4.72 \\
\hline $\begin{array}{l}\text { Sheet weight (thermosetting grid } \\
\text { included) }\end{array}$ & $2020 \mathrm{~g} / \mathrm{m}^{2}$ \\
\hline Sheet equivalent design thickness & $0.254 \mathrm{~mm}$ \\
\hline Ultimate load of one cord & $1517 \mathrm{~N}$ \\
\hline Sheet ultimate tensile strength & $2820 \mathrm{MPa}$ \\
\hline Elastic modulus & $190 \mathrm{GPa}$ \\
\hline Ultimate strain & $1.50 \%$ \\
\hline
\end{tabular}

the edge of the reinforced sides. No transversal connection was placed across the thickness of the wall specimens, so avoiding any sort of confining effect. The final thickness of the wall specimens reinforced with UHTSS was about $330 \mathrm{~mm}$ (Fig. 4b).

\section{Testing apparatus and loading protocol}

Shear-compression tests were performed on walls specimens using the testing apparatus showed in Figure 5. It consists of a couple of rigid steel plates, measuring $30 \mathrm{~mm}$ in thickness and mounted around the wall specimen to reproduce a shear box. A vertical actuator was used to impose the axial load $N$ to the

b)

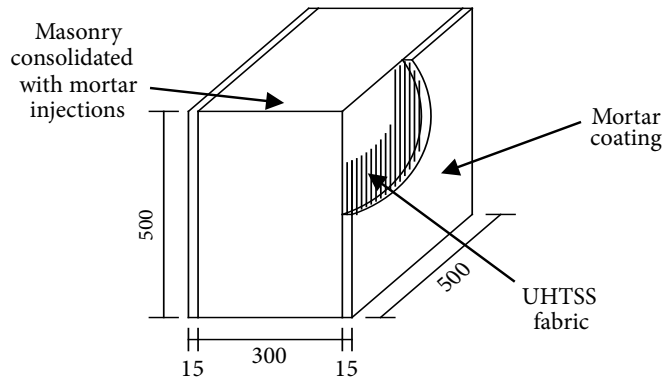

Fig. 4. Photo of the Ultra High Tensile Steel Sheets (UHTSS): detail of the high carbon steel cords with a micro-fine zinc galvanized coating (a); Schematic of the position of the outer reinforcement in UHTSS (b) 


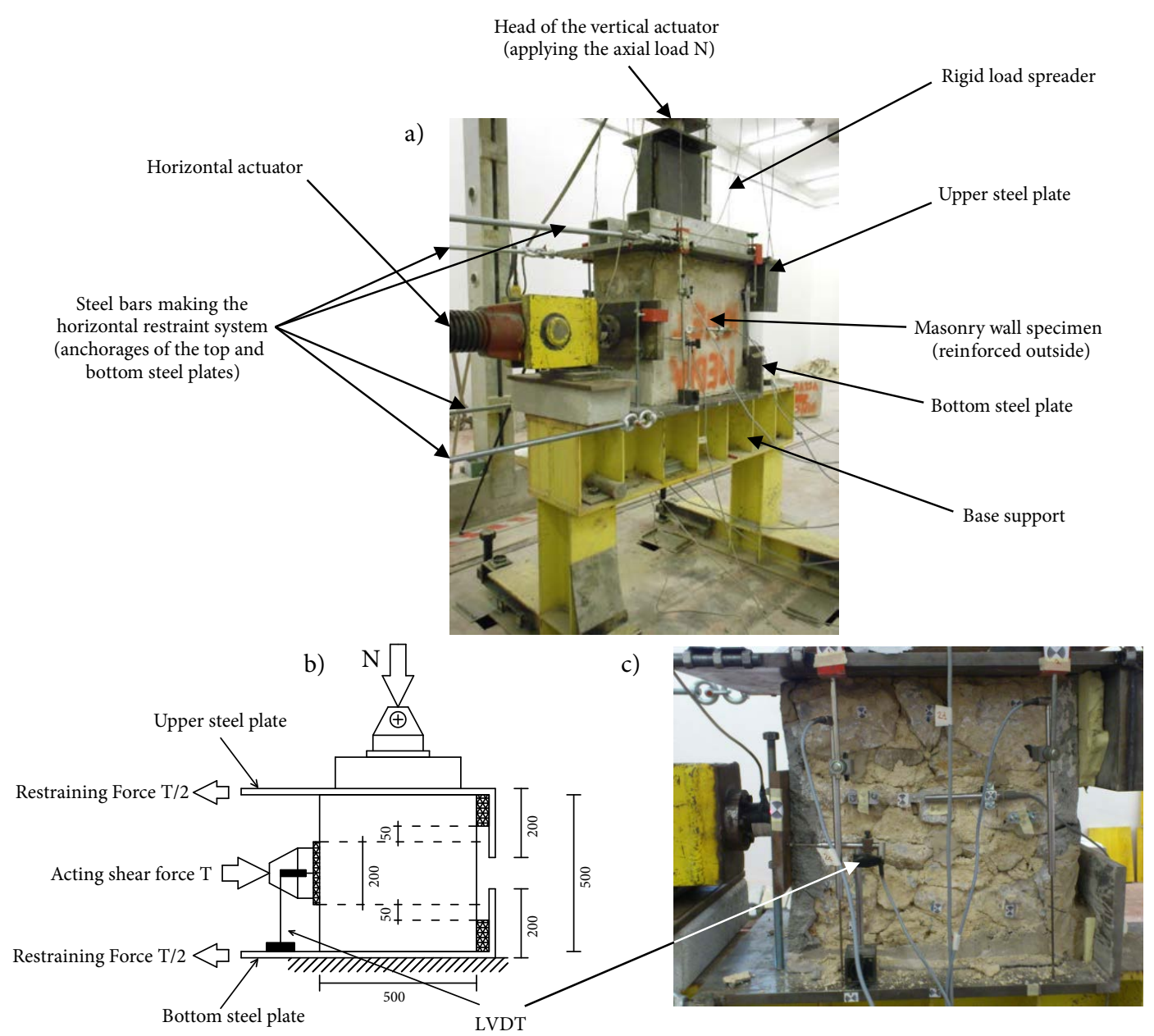

Fig. 5. Photo of the testing apparatus (a); Schematic and main dimensions (in mm) (b); Detail of one of the horizontal LVDT, fixed to the restrained bottom plate and pointing to the actuator head plate (c). A second LVDT is mounted on the other side of the specimens

specimen. To ensure a good contact among the rigid steel plates and the horizontal bases of the wall specimen, fluid cement mortar was previously distributed on the contact surfaces. The proper diffusion of the vertical load $N$ was ensured by two rigid apparatuses mounted on top of the upper plate and below the bottom one respectively. A second actuator was used to apply a horizontal shear force $T$ at mid height of the wall specimen. The central portion of the specimen was so forced to slide with respect to the upper and lower portions, which are restrained by the vertical sides of the steel plates (Fig. 5).

The shear-compression test was carried out in two separate steps. In the first step the vertical load $N$ was gradually applied up to the final value of about $27.5 \mathrm{kN}$. This value for $N$ represented about $1 / 3$ of the maximum load-carrying capacity previously recorded during the compression test carried out on the prototype wall specimen. In the second step, the horizontal actuator was set to move at the constant speed of
$1.5 \mathrm{~mm} / \mathrm{min}$, causing the central part of the wall specimen to slide with respect to the upper and lower parts (Fig. 6). While the sliding took place, the axial load $N$ was kept constant, and the current shear load values $T$ were recorded together with the displacements.

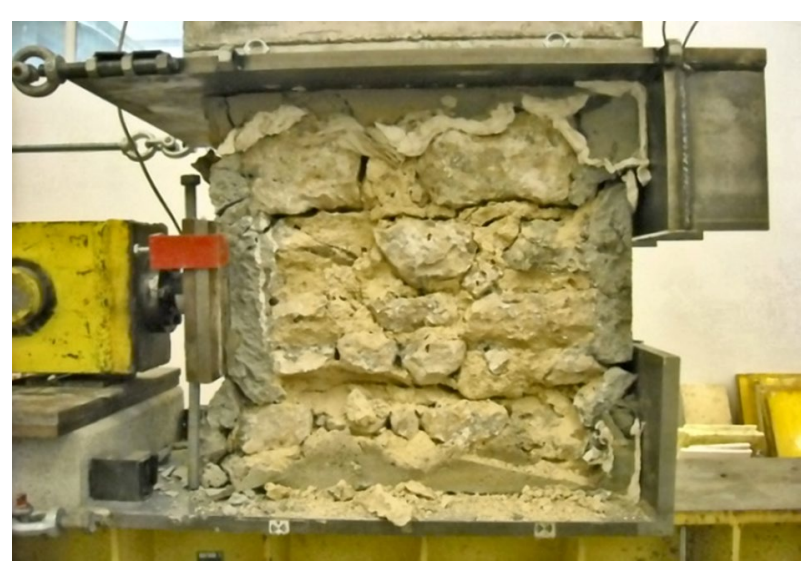

Fig. 6. Photo of a wall specimen the central portion of which is sliding with respect to the upper and lower parts 
The shear forces $T$ were detected by a $300 \mathrm{kN}$ loading cell with the precision of $0.1 \mathrm{kN}$. The relative displacement between the central portions of the specimens and the lower part were measured with a couple of LVDTs mounted on both sides of the wall specimens (Fig. 5b, c) and characterized by an accuracy of $1 / 100$ $\mathrm{mm}$ : the average of the two measurements has been considered.

\section{Experimental results and discussion}

Figure 7 plots the values of the shear force $T$ versus the relative displacement recorded between the central portions of the specimens and the lower part. The solid black curves refer to the wall specimens consolidated only with mortar injections. These curves exhibit a first, almost linear branch; a subsequent softening behaviour; and a final plastic horizontal tail. The two specimens reached the maximum shear force of about 65 and $75 \mathrm{kN}$ respectively for a relative displacement value of about $10 \mathrm{~mm}$, showing some small differences in stiffness. After the peak strength was attained, both specimens showed a plastic behaviour. The maximum

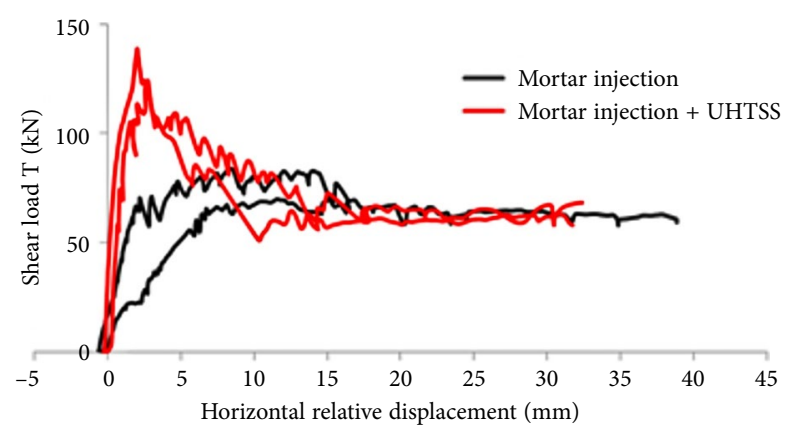

Fig. 7. Shear load vs. horizontal relative displacements recorded during the experimental tests shear force recorded from the specimens remained constant even at relative displacements of $35 \mathrm{~mm}$ and over. Unfortunately, one of the tests had to be stopped earlier (at $17 \mathrm{~mm}$ ) due to technical problems.

The solid red curves refer to walls specimens consolidated with mortar injection and reinforced with UHTSS. Compared to the unreinforced specimens, the use of external reinforcements provided much higher strength and stiffness. The two wall specimens reinforced with UHTSS reached the maximum shear strength values of about $125 \mathrm{kN}$ and $140 \mathrm{kN}$ respectively. Since these shear peak values were recorded at the relative displacements of about $3 \mathrm{~mm}$, wall specimens reinforced with UHTSS resulted to be about six times stiffer than the unreinforced wall specimens.

The post-peak behaviour of the specimens reinforced with UHTSS was characterized by a long softening branch, with the shear force quickly reducing towards a residual final value. This residual shear strength value was found to be similar to the maximum shear strength measured on masonry wall specimens consolidated with injection and not reinforced outside. This mechanical behaviour of the specimens reinforced with UHTSS was found to depend on the progressive delamination process occurring in the outer reinforcement. Once the maximum shear strength of the reinforced specimens is reached, the outer reinforced layer starts detaching from the wall becoming progressively more and more unstable in their plane. At the end of this process, when the reinforced layer is completely lost on both sides of the specimen (Fig. 8), the strength capacity of the specimen approaches the corresponding value of the unreinforced specimen.
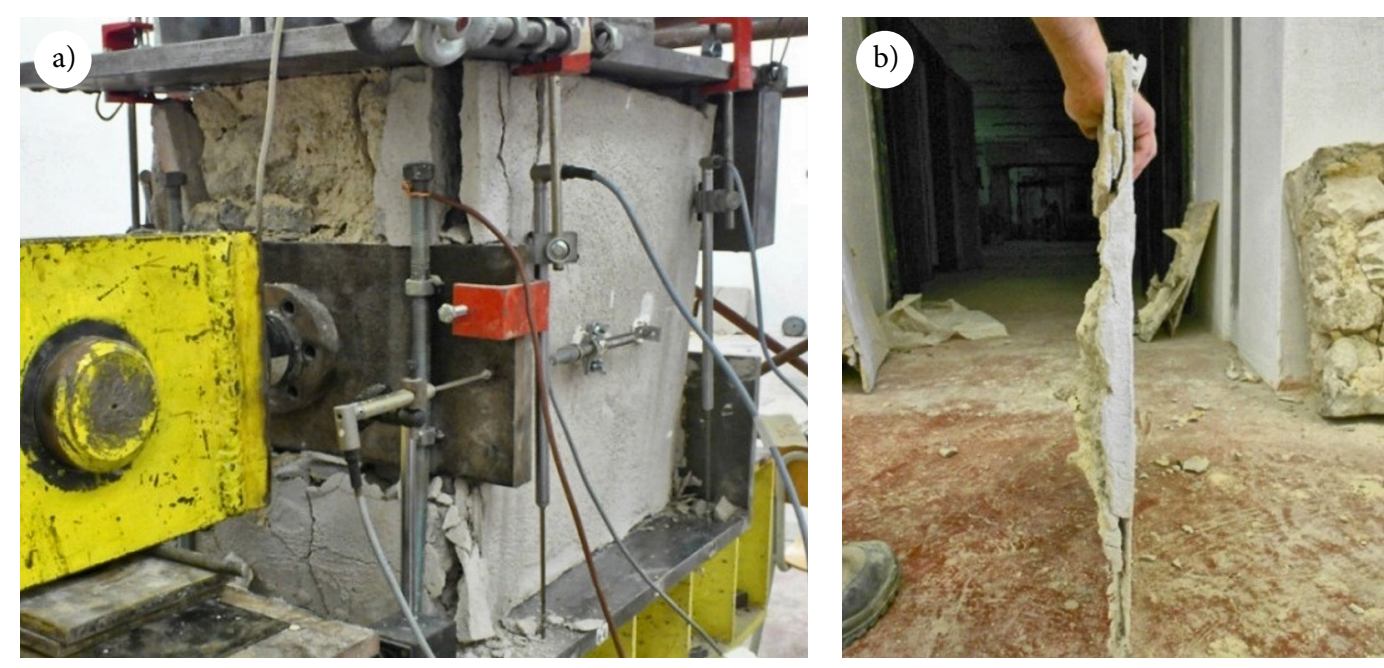

Fig. 8. External reinforcements delaminated from wall specimens 


\section{Numerical simulations}

\subsection{Presentation of the model}

In order to reproduce the experimental tests and to better understand the debonding failure mechanism of the external reinforcement, a nonlinear Finite Element Model (FEM) was implemented in ANSYS code v.13.0. The model is shown in Figures 9a and 9b, where the masonry specimen is represented in cyan, the testing apparatus in purple, and the mortar of the external reinforcement in green colour.

Solid 185 type (three-dimensional eight nodes isoparametric) elements have been used to schematize the masonry and testing apparatus. Since the experimental failure mechanism occurred due to the sliding of the central part of the specimen with respect of the upper and lower parts, the specimen was divided into three parts separated by two sliding surfaces. The bond between the three parts was modelled through contact plane elements (Targe 170, Conta 174) placed at their interfaces (Fig. 9c). Using these elements, several contact laws can be assumed. In this case, a bilinear cohesive law was assumed, allowing the separation and the slip of the contact surfaces in accordance with the bilinear model plotted in Figure 10. In this model $\sigma$ and $\tau$ are the normal and the shear contact stress respectively, $u$ and $\delta$ are the contact gap and the tangential slip between the two planes. The constitutive interface model shows a first linear loading behaviour that is followed by linear softening branch, meaning that when the maximum normal contact stress $\sigma_{n}$ is achieved, a separation begins. This separation is completed when the contact gap reaches $u_{n}$. Similarly, when the shear stress $\tau_{f}$ is achieved, delamination occurs and ends when the relative displacement reaches $\delta_{f}$ for which the shear stress is zero. The areas $G_{n}$ and $G_{f}$ in Figure 10, defined as the critical fracture ener- gies, represent the amount of energy released during the separation and the delamination phenomena. The variables $u_{1}$ and $\delta_{1}$ are determined from the elastic properties (the Young's modulus $E$ and the Poisson's ratio $v$ ) of the material.

The three parts of the specimen were regarded as elastic because all nonlinear behaviour, due to failure mechanism, was concentrated on the sliding surfaces. Table 3 reports the values selected for $E$ and $v$. The choice of the most appropriate value of $E$ was based on compressive strength of unreinforced specimen and on an Italian standard recommendations (Circolare 617/2009). The Italian standard suggests, for a similar masonry typology, a minimum values of compressive strength and Young's modulus respectively of $f_{c}=$ $1.00 \mathrm{MPa}$ and $E=690 \mathrm{MPa}$. Since the measured compressive strength of specimen was $f_{c}=0.6 \mathrm{MPa}$, less than the Italian standard minimum value, it was possible to assume for the masonry of the unreinforced specimen $E=500 \mathrm{MPa}$. For the specimen reinforced with mortar injection it was assumed $f_{c}=1.2 \mathrm{MPa}$ and $E=1000 \mathrm{MPa}$, because the Italian standard suggests an amplificatory factor of 2 for the mechanical properties of the masonry reinforced with this technique.

Table 3. Elastic parameters

\begin{tabular}{|c|c|}
\hline \multicolumn{2}{|c|}{ Wall specimen } \\
\hline Young's modulus $E$ & $1000 \mathrm{MPa}$ \\
\hline Poisson's ratio $v$ & 0.2 \\
\hline \multicolumn{2}{|c|}{ Wall specimen elements near the sliding surface } \\
\hline Young's modulus $E$ & $500 \mathrm{MPa}$ \\
\hline Poisson's ratio $v$ & 0.2 \\
\hline \multicolumn{2}{|c|}{ Testing apparatus elements } \\
\hline Young's modulus $E$ & $210000 \mathrm{MPa}$ \\
\hline Poisson's ratio $v$ & 0.2 \\
\hline
\end{tabular}
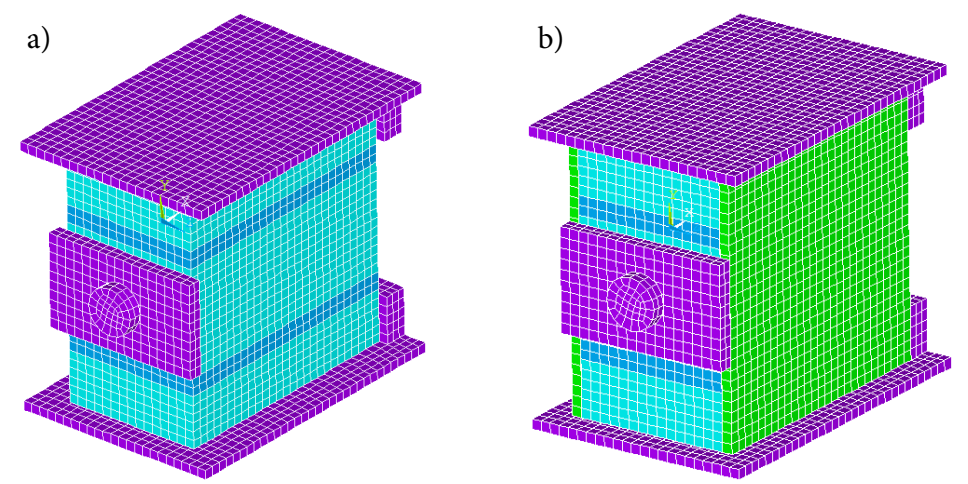

c)

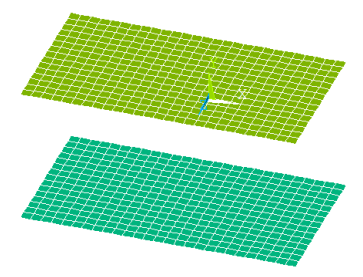

Fig. 9. FEM of the unreinforced wall specimen (a); FEM of UHTSS reinforced specimen (b); contact plane elements at the interfaces of the three parts of the wall specimen $(c)$ 
The elements near the sliding surfaces, represented in blue colour in Figure 9a, had $E=500 \mathrm{MPa}$ to account for the cracking phenomenon of the mortar joints where the sliding occurred, according to experimental evidence (Fig. 6).

The elements of testing apparatus had also an elastic behaviour, with the mechanical properties of steel.

The bond-separation and bond-slip relationships are defined by $\sigma_{n}, G_{n}, \tau_{f}$ and $G_{f}$ (Fig. 10). The value assigned to $\sigma_{n}$ was $0.12 \mathrm{MPa}$, equal to the masonry tensile strength calculated as $f_{t}=0.1 f_{\mathcal{c}}$, and a low value of $0.01 \mathrm{~N} / \mathrm{mm}$ was assigned to $G_{n}$ in order to confer a brittle separation behaviour.

The value of $\tau_{f}$ was evaluated as it follows. A mean value of maximum shear forces $T_{\max }$ equal to $70 \mathrm{kN}$ was measured in the two specimens reinforced only with mortar injection: this force was applied to the central part of specimen and transferred to the upper and lower parts through the two contact surfaces. Each surface transferred a force of $T_{\text {max }} / 2=35 \mathrm{kN}$. The area $A$ of the surfaces was $1620 \mathrm{~cm}^{2}$. Since it was observed that the upper part of the specimen was lifted up during the test, it was assumed that the contact area was the $95 \%$ of $A$ : so the calculated value of $\tau_{f}$ is:

$$
\tau_{f}=\frac{T_{\max }}{2 \cdot A \cdot 0.95}=0.23 \mathrm{MPa} .
$$

The experimental load-displacement curves show a long horizontal portion after the maximum force, so the value assigned to $G_{f}$ was very high, equal to $60 \mathrm{~N} /$ $\mathrm{mm}$.

The mortar of the outer reinforcement (the plaster) was modelled by means of Solid 65 elements. A non-linear behaviour defining a Drucker-Prager (DP) yield criterion (Drucker, Prager 1952) can be assigned to this type of element. This criterion defines the elastic limits of the material under combined states of stress. It consists of a domain in the principal stress space, that is delimited by a surface. The DP surface has a

a)

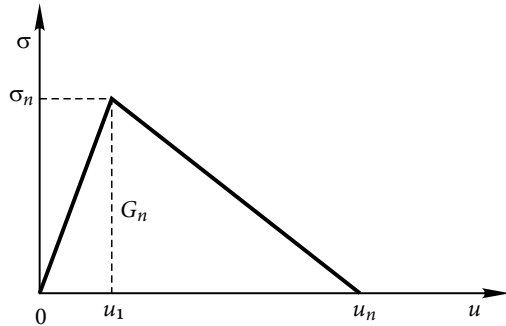

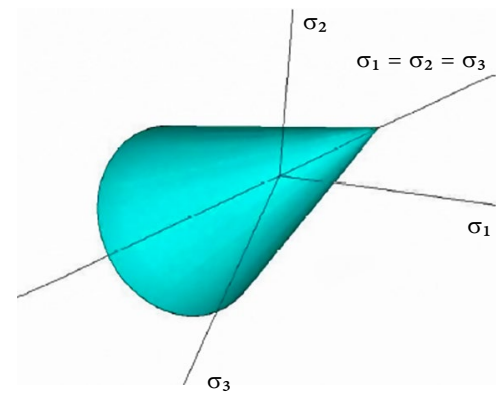

Fig. 11. Drucker-Prager surface in the principal stress space

shape of cone with right meridians (Fig. 11): when the stress state reaches the DP surface, plastic deformation occurs with constant stress level.

The material parameters required to define the DP yield surface are the cohesion $c$, the internal friction angle $\phi$ and the flow angle $\eta . c$ and $\phi$ are related to the mortar uniaxial tensile strength $f_{t}$ and the uniaxial compressive strength $f_{c}$ as it follows:

$$
\begin{gathered}
c=\frac{f_{c} f_{t}}{f_{c}-f_{t}} ; \\
\phi=\operatorname{Sin}^{-1}\left(\frac{f_{c}-f_{t}}{f_{c}+f_{t}}\right),
\end{gathered}
$$

while $\eta$ it is generally assumed equal to $0.5 \cdot \phi$.

The mechanical properties of the mortar (Table 4) were derived from a technical report provided by the manufacturer, where the results of experimental tests for flexural and compressive strength were reported. According to the Italian standard (D.M. 14/1/2008), the tensile strength was calculated from flexural tensile strength as it follows:

$$
f_{t}=\frac{f_{f t}}{1.2}=2.58 \mathrm{MPa}
$$

Table 5 reports the DP parameters calculated with the value of mortar tensile strength and compressive strength.

The UHTSS was modelled by plane elements Shell 181 (isoparametric two-dimensional elements

b)

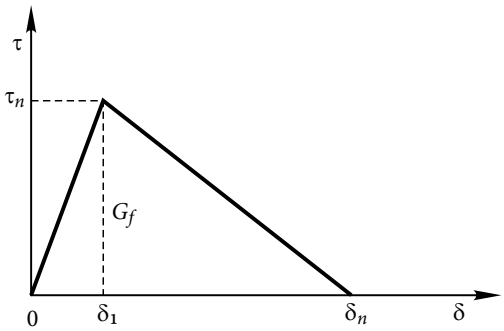

Fig. 10. Bilinear cohesive laws adopted for the separation and the sliding behaviour 
Table 4. Mechanical properties of the mortar

\begin{tabular}{|l|c|}
\hline Young's modulus $E$ & $9451.27 \mathrm{MPa}$ \\
\hline Uniaxial compression strength $f_{c}$ & $10.47 \mathrm{MPa}$ \\
\hline Flexural tensile strength $f_{f t}$ & $3.10 \mathrm{MPa}$ \\
\hline
\end{tabular}

Table 5. Material parameters assigned to the plaster

\begin{tabular}{|l|c|}
\hline Young's modulus $E$ & $9451.27 \mathrm{MPa}$ \\
\hline Poisson's ratio $v$ & 0.2 \\
\hline Cohesion $c$ & $1.79 \mathrm{MPa}$ \\
\hline Friction angle $\phi$ & $52.30^{\circ}$ \\
\hline Flow angle $\eta$ & $26.15^{\circ}$ \\
\hline
\end{tabular}

with four nodal points), with equivalent thickness $t=0.254 \mathrm{~mm}$ : the material assigned was orthotropic linear-elastic, with $E=190000 \mathrm{MPa}$ for the fibre direction and $E=0$ for the other direction. The shell elements were attached to the internal face of the solid elements of the mortar panels.

The bond between mortar and masonry was always modelled through Targe 170 e Conta 174 elements with a bilinear cohesive law: in this case only the bond-slip behaviour was considered. The values assigned to $\tau_{f}$ and $G_{f}$ are reported in Table 6: they were calibrated to reproduce three direct shear tests described in the manufacturer's report. The tests were performed on specimens composed of a single clay brick acting as the masonry substrate, externally strengthened with steel cord embedded in the mortar (Fig. 12). The aim was to investigate the bond behaviour of the reinforcement system with the masonry.
The tests were reproduced using the analytical solution presented in Yuan et al. 2004, in which the bi-linear cohesive law is employed for the prediction of the entire debonding propagation process in a shear test of a plate-to-substrate bonded joint. By assuming an infinitely rigid support; by assigning to the plate width $b$, the thickness $t$ and the bonded length $L$ the corresponding values of the UHTSS in the test $(b=$ $65 \mathrm{~mm}, t=0.084 \mathrm{~mm}, L=200 \mathrm{~mm}$ ); and by defining the bi-linear cohesive law with the following bond-slip parameters:

$$
\tau_{f}=0.8 \mathrm{MPa}, G_{f}=1.5 \mathrm{~N} / \mathrm{mm} .
$$

The numerical solution provided a force-displacement curve of the shear test that was in good agreement with the experimental curves (Fig. 13).

For the definition of the bond-slip parameters of the plaster masonry interface of the model, the value of the maximum shear stress $\tau_{f}$ was halved to account for the presence of the mortar joints on the masonry support surface (Fig. 6) and to account that the bond on stone is smaller than on clay brick, as pointed out by De Felice et al. 2014, where the results of direct shear tests of specimens composed of clay bricks and of stone elements are reported.

Table 6. Bond-slip model parameters of plaster-masonry interface

\begin{tabular}{|l|l|}
\hline Bond strength $\tau_{f}$ & $0.4 \mathrm{MPa}$ \\
\hline Interfacial fracture energy $G_{f}$ & $1.5 \mathrm{MPa}$ \\
\hline
\end{tabular}
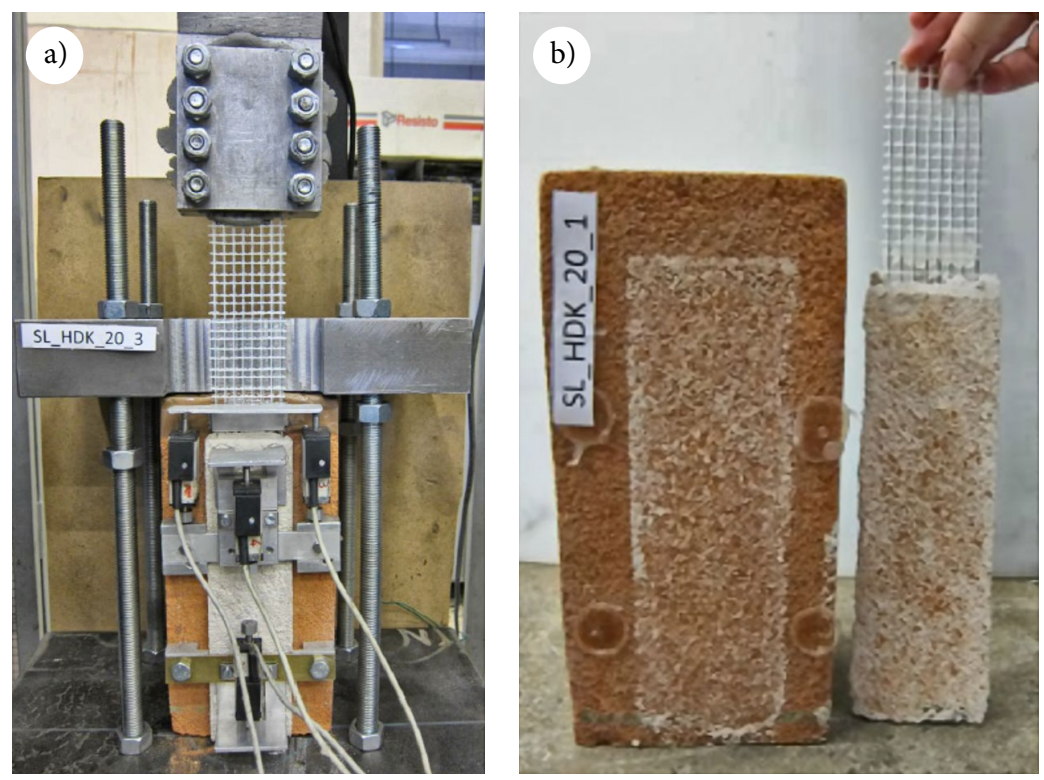

Fig. 12. Direct shear test described in manufacturer's report (a); failure mode of a test (b) 
The nonlinear analysis was carried out in two phases: in the first phase a uniform pressure was applied on the horizontal upper plate of the apparatus to represent the vertical load; in the second phase, the displacement of the horizontal actuator (represented by the cylinder element) was gradually increased in $\mathrm{x}$ direction from $0 \mathrm{~mm}$ to $20 \mathrm{~mm}$, while the remaining parts of the apparatus remained constrained (Fig. 14). At each step, the value of the reaction force $T$ along the $\mathrm{x}$ direction resulting from the applied displacement was computed and recorded. The nonlinear system of equations was solved by an incremental NewtonRaphson method.

\subsection{Nonlinear analysis results}

Figures 15 and 16 show the load-displacement curves resulting from the analysis of the specimen reinforced with mortar injection only and in combination with

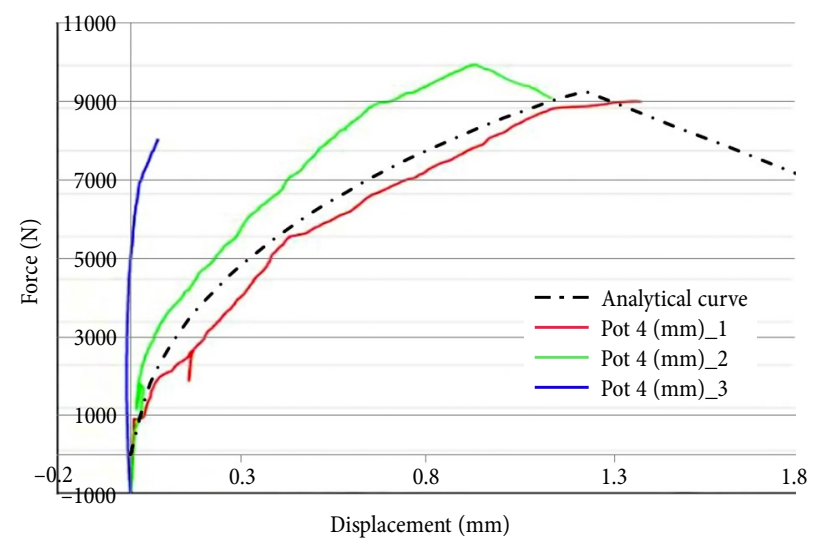

Fig. 13. Force-displacement curves of direct shear tests and of numerical solution

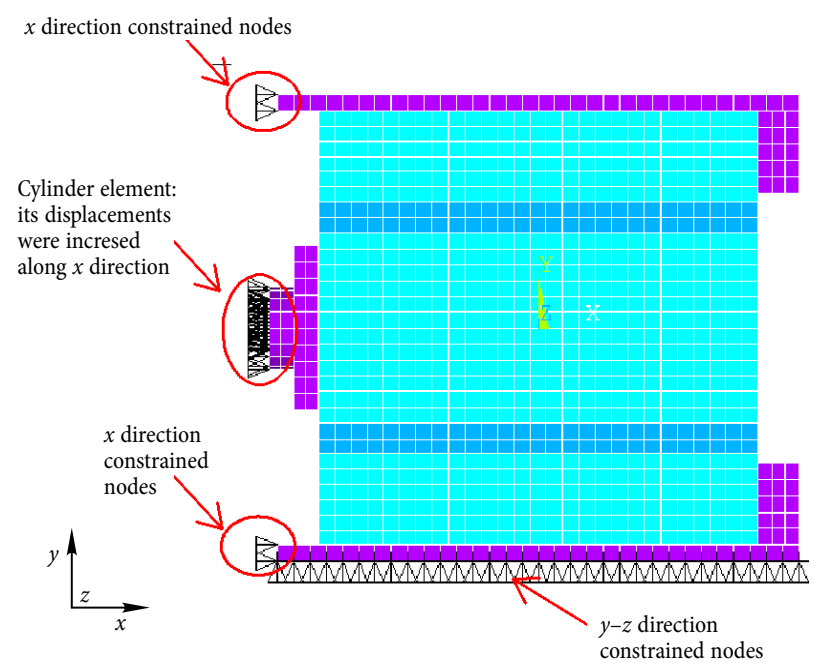

Fig. 14. Displacements and constraints applied to the nodes of the model
UHTSS, respectively. A good numerical-experimental agreement can be noticed: the maximum shear force and the displacements compare quite well. The numerical analyses stopped due to convergence problems. The curves are characterized by a loss of stiffness when sliding begins. Figure 17 shows the contour of the contact shear stress along the interfaces among the three parts of the unreinforced wall specimen. Sliding began when the shear stress reached the value of $0.230 \mathrm{MPa}$ : the blue zones, where stress values are close to zero, are the detachment areas due to normal separation of the surfaces. The maximum load was reached when the shear stress attained $\tau_{f}$ over the entire contact surfaces.

The model of the UHTSS reinforced specimens revealed that the failure mechanism of the reinforcement was its loss of adhesion from the wall specimen. Debonding started near the steel plate transferring the load and near the vertical supports (red areas in Fig. 18a). Debonding zones gradually increased with shear load, until almost all the mortar-masonry interface reached the contact shear stress $\tau_{f}=0.4 \mathrm{MPa}$ (Fig. 18c).

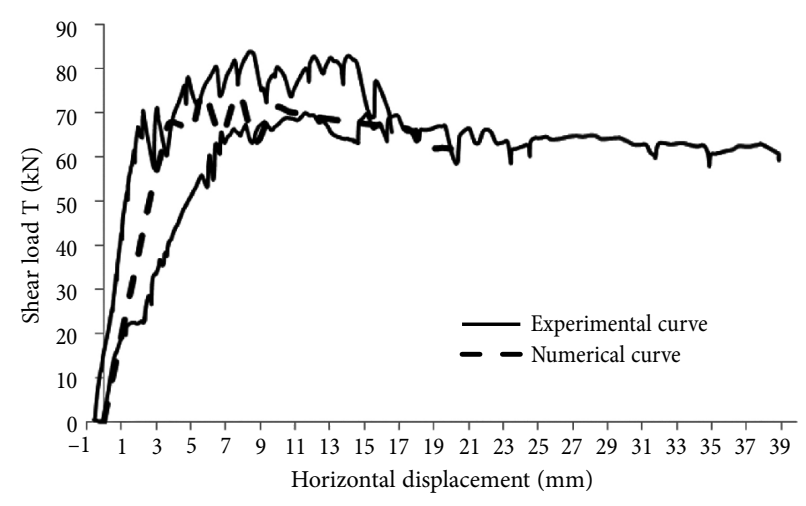

Fig. 15. Nonlinear analysis results from FEM reproducing walls specimen reinforced with mortar injections only: load-displacement curve compared to experimental curves

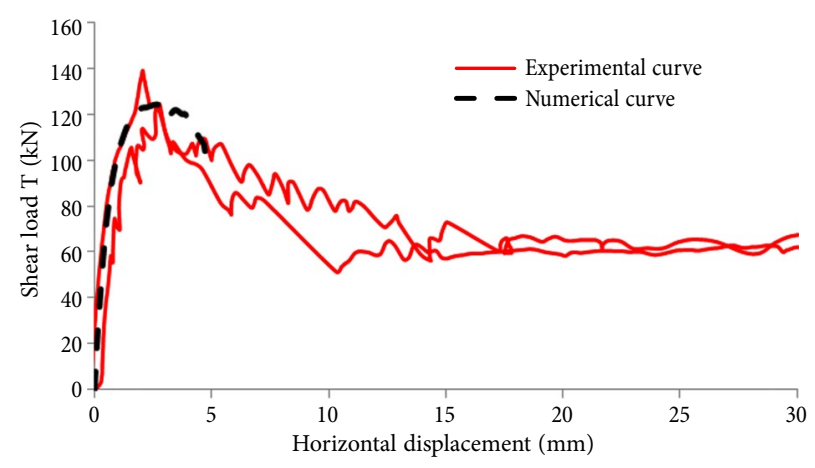

Fig. 16. Nonlinear analysis result from FEM reproducing specimen reinforced with mortar injections and UHTSS: load-displacement curve compared to experimental curves 


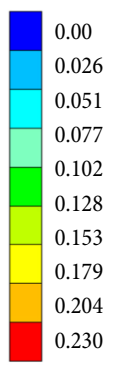

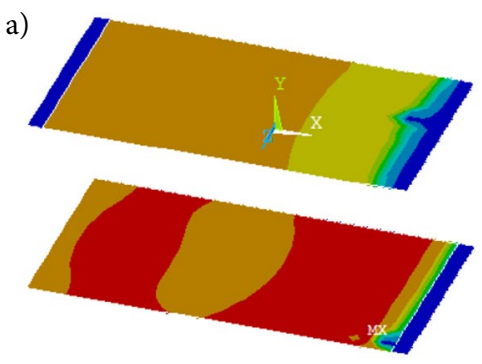

$T=60.30 \mathrm{kN}$

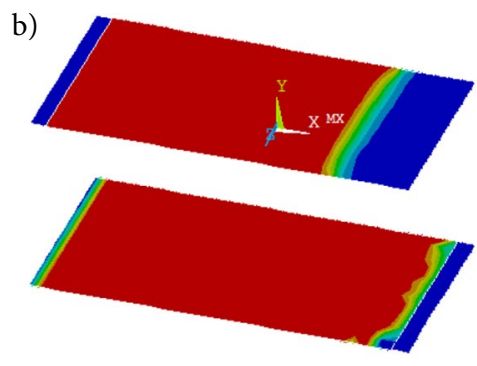

$T=74.52 \mathrm{kN}$

Fig. 17. Contact shear stresses, expressed in $\mathrm{MPa}$, along sliding surfaces for two values of shear load

a)

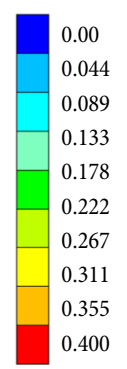

b)

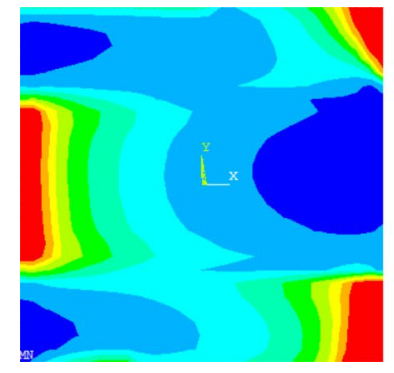

$T=34.94 \mathrm{kN}$

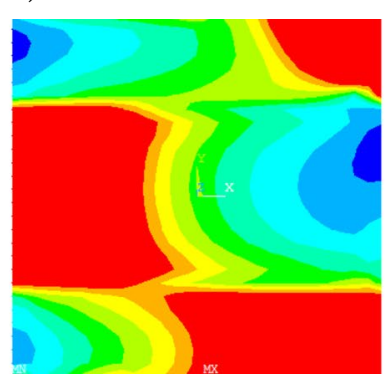

$T=78.65 \mathrm{kN}$ c)

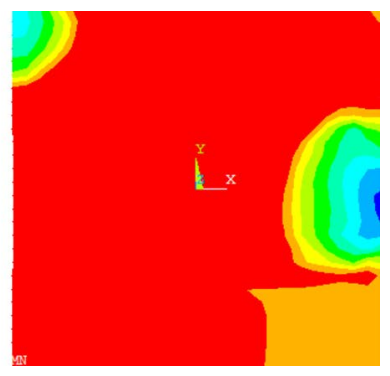

$T=113.14 \mathrm{kN}$

Fig. 18. Contact shear stresses, expressed in MPa, on sliding mortar-masonry interface for three values of shear load

The model also showed that the external reinforcing layers remains nearly undamaged and the debonding phenomenon occurs before the UHTSS nets could actively participate. In conclusion, through the FEM model, it was possible to confirm the results of the experimental tests.

\section{Conclusions}

The present research investigates the behaviour of masonry panels subjected to shear-compression loads. Laboratory tests were performed on historical masonry wall specimens prepared in accordance with the original materials and constructive technique, then strengthened with injections of special mortars and with UHTSS applied as outer reinforcement. A comparison between numerical simulations and experimental results was carried out to better understand critical features of the strengthening techniques. Wall specimens reinforced with mortar injections only reached their maximum shear response after large displacement, and showed an almost perfectly plastic behaviour up to relative displacements of several dozens of millimetres. Compared to wall specimens not reinforced outside, the behaviour of the wall specimens reinforced with UHTSS was characterized from a much higher shear peak response and from similar residual shear values. Reinforcing plaster made with UHTSS delaminated from the masonry substrate and remained undamaged, causing a post-peak softening behaviour. Similar response was recorded also from numerical simulations . For this reason, higher structural bond between the external fibre composites reinforcements and the masonry substrate would be suitable in order to improve the reinforcement effectiveness. On the other hand, introducing lighter fabrics characterized from weaker fibres and larger net openings would help improve bond of the outer reinforcement to the masonry substrate and would improve both the damage spread and the energy dissipation process through the applied reinforcement. In the practice, the reinforcing fabrics are often applied to masonry walls with transversal connections to lock them that, in any case, give a contribution to the beneficial effects mentioned above. The use of these connections has been intentionally avoided in this study, so as to investigate the efficiency of the external reinforcement only. In the future, new experiments and FEM simulations will be carried out to demonstrate the main features of the reinforcing fabrics relates to strength, stiffness and energy dissipation of ancient masonry walls. 


\section{References}

Ameri, G.; Augliera, P.; Bindi, D.; D’Alema, E.; Ladina, C.; Lovati, S.; Luzi, L.; Marzorati, S.; Massa, M.; Pacor, F.; Puglia, R. 2009. Strong-motion parameters of the $M w=6.3$ Abruzzo (Central Italy) earthquake: open file report [online], [cited 21 May 2009]. INGV. Available from Internet: http://ismd. mi.ingv.it/accel/statiche/rapporti_tecnici/08-2009.pdf

Ceci, A. M.; Contento, A.; Fanale, L.; Galeota,D.; Gattulli, V.; Lepidi, M.; Potenza, F. 2010. Structural performance of the historic and modern buildings of the University of L'Aquila during the seismic events of April 2009, Engineering Structures 32(7): 1899-1924.

http://dx.doi.org/10.1016/j.engstruct.2009.12.023

Chiaraluce, L.; Chiarabba, C.; De Gori, P.; Di Stefano, R.; Improta, L.; Piccinini, D.; Schlagenhauf, A.; Traversa, P.; Valoroso, L.; Voisin, C. 2009. The 2009 L'Aquila (Central Italy) seismic sequence, Bollettino di Geofisica Teorica e Applicata [online], [cited 03 October 2011]. INGV. Available from Internet: ftp://ftp.ingv.it/pub/luisa.valoroso/MyPapers/ Chiaraluce_EtAl_BGTA_2011.pdf

Chioccarelli, E.; De Luca, F.; Iervolino, I. 2009. Preliminary study of L'Aquila Earthquake ground motion records v.5.20: open file report [online], [cited 2009]. ReLuis. Available from Internet: http://www.reluis.it.

Circolare 617/2009. Istruzioni per l'applicazione nuove norme tecniche costruzioni di cui al Decreto Ministeriale 14 gennaio 2008. Italian Standard.

CNR DT 200/204: 2004. Guide for the design and construction of externally bonded FRP system for strengthening existing structures. Italian Standard.

De Felice, G.; De Santis, S.; Garmendia, L.; Ghiassi, B.; Larrinaga, P.; Lourenço, P. B.; Oliveira, D. V.; Paolacci, F.; Papanico- laou, C. G. 2014. Mortar-based system for externally bonded strengthening of masonry, Materials and Structures 47(12): 2021-2037. http://dx.doi.org/10.1617/s11527-014-0360-1

D.M. 14/1/2008. Nuove Norme Tecniche per le Costruzioni. Italian Standard.

Dominici, D.; Galeota, D.; Gregori, A.; Rosciano, E.; Elaiopoulos, M. 2011. Using new techniques of geomatic and structural control in the old city center of L'Aquila after the June 6, 2009 earthquake, in Joint International Symposium on Deformation Monitoring, 2-4 November 2011, Hong Kong, China.

Dominici, D.; Elaiopoulos, M.; Galeota, D.; Gregori, A. 2012. Post-earthquake geomatic survey of a monumental building in L'Aquila (Italy), in Proceedings of the Third International Symposium on Life-Cycle Civil Engineering (IALCCE'12), 3-6 October 2012, Vienna, Austria.

Dominici, D.; Galeota, D.; Gregori, A.; Rosciano, E.; Alicandro, M.; Elaiopoulos, M. 2014. Integrating geomatics and structural investigation in post-earthquake monitoring of ancient monumental Buildings, Journal of Applied Geodesy 8(2): 141-154. http://dx.doi.org/10.1515/jag-2012-0008

Drucker, D. C.; Prager, W. 1952. Soil mechanics and plastic analysis for limit design, Quarterly of Applied Mathematics 10(2): 157-165.

EN 1052-3: 2007. Methods of test for masonry - Determination of initial shear strength. European Standard.

Yuan, H.; Teng, J. G.; Seracino, R.; Wu, Z. S.; Yao, J. 2004. Fullrange behaviour of FRP-to-concrete bonded joints, Engineering Structures 26(5): 553-565.

http://dx.doi.org/10.1016/j.engstruct.2003.11.006

Franco DI FABIO. PhD, graduated in Structure Engineering in 1997 from University of L'Aquila. Researcher at the Department of Civil, Building and Environmental Engineering of University of L'Aquila from 2004. The research field is the evaluation of seismic vulnerability of reinforced-concrete and masonry structure. Teacher of the course "Masonry building" and of the Second Level Master in "Seismic Engineering" at the University of L'Aquila".

Amedeo GREGORI. PhD, ACI member, is a Researcher at the Department of Civil, Building and Environmental Engineering, University of L'Aquila, Italy. He's Visiting Researcher at the Center for Advanced Cement based Materials (ACBM), at the Northwestern University, Chicago, USA. He teaches "Special Constructions" and "Design of Structures" at the University of L'Aquila, where he also teaches at the Second Level Master Course in "Seismic Engineering". His research interests include structural behavior of high-performance concrete and materials, nondestructive testing, rheology, international bulding codes, seismic engineering.

Matteo TOTANI. Graduated in Civil Engineering in 2012. PhD student at the Department of Civil, Building and Environmental Engineering of University of L'Aquila from 2013. Research interests: seismic behavior of masonry structures, retrofitting techniques and innovative seismic devices. 